\title{
ON SHARPENING OF A THEOREM OF T. J. RIVLIN
}

\author{
N. K. Govil And S. Hans
}

Abstract. Let $p(z)=a_{0}+a_{1} z+a_{2} z^{2}+a_{3} z^{3}+\cdots+a_{n} z^{n}$ be a polynomial of degree $n$. According to a well-known theorem of Rivlin [11], if $p(z)$ is a polynomial of degree $n$ having no zeros inside the unit circle, then for $0<r \leqslant 1$,

$$
\max _{|z|=r}|p(z)| \geqslant\left(\frac{r+1}{2}\right)^{n} \max _{|z|=1}|p(z)| .
$$

In this paper, we generalize and sharpen the above result of Rivlin. Our result also sharpens a recently proved result of Govil and Nwaeze [3]. Also, we present some examples to show that in some cases the improvement obtained by our theorem can be considerably significant.

Mathematics subject classification (2010): 15A18, 30C10, 30C15, 30A10.

Keywords and phrases: Inequalities, polynomials, zeros.

\section{REFERENCES}

[1] N. K. Govil, On the maximum modulus of polynomials, J. Math. Anal. Appl. 112, (1985), $253-258$.

[2] N. K. Govil, Some inequalities of derivatives of polynomials, J. Approx. Theory 66, (1991), 29-35.

[3] N. K. Govil And E. R. NwaEzE, Some sharpening and generalizations of a result of T. J. Rivlin, Anal. Theory and Appl. 33, (2017), 219-228.

[4] N. K. Govil AND M. A. QAZI, On maximum modulus of polynomials and related entire functions with restricted zeros, Math. Inequal. Appl. 5, 1 (2002), 57-60.

[5] N. K. Govil, M. A. QAZI AND Q. I. RAHMAN, Inequalities describing the growth of polynomials not vanishing in a disk of prescribed radius, Math. Inequal. Appl. 6, 3 (2003), 453-467.

[6] G. V. Milovanović, D. S. Mitrinović and TH. M. Rassias, Topics in polynomials: Extremal Problems, Inequalities, Zeros, World Scientific Publishing Co. Pte. Ltd., 1994.

[7] M. A. QAZI, On the maximum modulus of polynomials, Proc. Amer. Math. Soc. 115, 2 (1992), $337-$ 343.

[8] Q. I. RaHman, Applications of functional analysis to extremal problems for polynomials, Les Presses de l'Université de Montréal, Montréal, Canada, 1967.

[9] Q. I. Rahman And G. Schmeisser, Les inégalitiés de Markov et de Bernstein, Les Presses de l’Université de Montréal, Montréal, Canada, 1983.

[10] Q. I. RAhman And G. SCHMEISSER, Analytic theory of polynomials, Oxford University Press, New York, 2002.

[11] T. J. Rivlin, On the maximum modulus of polynomials, Amer. Math. Monthly 67, (1960), 251-253.

[12] R. S. VARGA, A comparison of the successive overrelaxation method and semi-iterative methods using Chebyshev polynomials, J. Soc. Indust. Appl. Math. 5, (1957), 39-46. 